\title{
Determinants of gross motor skill performance in children with visual impairments
}

\author{
Pamela S. Haibach ${ }^{\mathrm{a}, *}$, Matthias O. Wagner ${ }^{\mathrm{b}}$, Lauren J. Lieberman ${ }^{\mathrm{a}}$ \\ ${ }^{a}$ Department of Kinesiology, Sport Studies, and Physical Education, The College at Brockport, State University of New York, United States

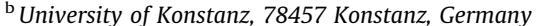

A R T I C L E I N F O

Keywords:

Gross motor skills

Children

Visual impairment

Blind

Age

Gender

\begin{abstract}
A B S T R A C T
Children with visual impairments (CWVI) generally perform poorer in gross motor skills when compared with their sighted peers. This study examined the influence of age, sex, and severity of visual impairment upon locomotor and object control skills in CWVI. Participants included 100 CWVI from across the United States who completed the Test of Gross Motor Development II (TGMD II). The TGMD II consists of 12 gross motor skills including 6 object control skills (catching, kicking, striking, dribbling, throwing, and rolling) and 6 locomotor skills (running, sliding, galloping, leaping, jumping, and hopping). The full range of visual impairments according to United States Association for Blind Athletes (USABA; B3 20/200 20/599, legally blind; B2 20/600 and up, travel vision; B1 totally blind) were assessed. The B1 group performed significantly worse than the B2 $(0.000 \leq p \leq 0.049)$ or B3 groups $(0.000 \leq p \leq 0.005)$; however, there were no significant differences between B2 and B3 except for the run ( $p \quad 0.006)$, catch $\left(\begin{array}{ll}p & 0.000\end{array}\right)$, and throw ( $p$ 0.012). Age and sex did not play an important role in most of the skills, with the exception of boys outperforming girls striking ( $p$ 0.009), dribbling ( $p$ 0.013), and throwing ( $p$ 0.000), and older children outperforming younger children in dribbling ( $p$ 0.002). The significant impact of the severity of visual impairment is likely due to decreased experiences and opportunities for children with more severe visual impair ments. In addition, it is likely that these reduced experiences explain the lack of age related differences in the CWVI. The large disparities in performance between children who are blind and their partially sighted peers give direction for instruction and future research. In addition, there is a critical need for intentional and specific instruction on motor skills at a younger age to enable CWVI to develop their gross motor skills.
\end{abstract}

Children with visual impairments are developmentally behind their sighted peers in motor skill competence (e.g. Houwen, Visscher, Lemmink, \& Hartman, 2009; Wagner, Haibach, \& Lieberman, 2013). These lower performances may be caused in part by reduced opportunities to participate in physical activities (Holbrook, Caputo, Fuller, Perry, \& Morgan, 2009; Kozub \& Oh, 2004a, 2004b; Lieberman \& MacVicar, 2003; Shapiro, Moffett, Lieberman, \& Dummer, 2005), often resulting from a lack of knowledge on the part of physical educators on how to appropriately modify curriculum and equipment for the specific needs of this population (Conroy, 2012; Lieberman, Houston Wilson, \& Kozub, 2002; Perkins, Columna, Lieberman, \& Bailey, 2013). By using modified equipment, children with visual impairments may participate in similar motor skills and activities with their sighted peers. Physical educators need not worry that using modified equipment will impair sighted

\footnotetext{
* Corresponding author at: SUNY College at Brockport, 350 New Campus Drive, Brockport, NY 14420, United States. Tel.: +1 5853955427. E-mail addresses: phaibach@brockport.edu, pamelaseidle@gmail.com (P.S. Haibach).
} 
children's performance, as it has been found that sighted children perform similarly with the modified equipment as they do with typical sports equipment (Lieberman, Haibach, \& Wagner, 2014). In order to ensure appropriate instruction and guidance to teach gross motor skills, instructors must have knowledge about the specific personal attributes of the children with visual impairments such as age, gender, and level of visual impairment.

During typical child development, gross motor coordination gradually improves with increasing age (Butterfield, Angell, \& Mason, 2012; Ulrich, 2000; Vandorpe et al., 2011); however, this may not occur in children with visual impairments and blindness. Unfortunately, the influence of age upon motor skill performance has not been well established in children with visual impairments. Two studies found no differences between younger and older children with visual impairments aged 813 years (Bouchard \& Tetreault, 2000) and 613 years (Pereira, 1990), while another study (Gipsman, 1981) found better performances in older children (12 14 years) in comparison to younger children ( 810 years) who are blind on dynamic balance. Age effects were found for a manual dexterity task, finding progressively shorter times to complete the task for older children, but, this age effect was minimal for children who were blind (Reimer, Smits Engelsman, \& Siemonsma Boom, 1999). Further research is necessary to establish a relationship between age and gross motor performances in children with visual impairments, as the only known research on a gross motor skill was on dart throwing, in which older children (14 21 years) were found to perform significantly better on a dart throwing task in comparison to younger children ( 714 years) who were blind (Joseph, 1984).

There is much research to support gender differences in sighted children for motor skill performances, in particular, object control skills such as throwing and striking (Barnett, van Beurden, Morgan, Brooks, \& Beard, 2010; Butterfield \& Loovis, 1998; Butterfield et al., 2012; Thomas \& French, 1985). Research on gross motor skill gender differences in children who are blind, on the other hand, is scant, with only one known study examining gender differences in dart throwing finding boys outperforming girls (Joseph, 1984). Interventions for sighted children with a focus upon improving mechanics have yielded more significant benefits for girls than boys (Thomas, Michael, \& Gallagher, 1994), indicating a lack of practice may be a large contributor to these gender differences. The most effective programs have emphasized the development of kicking, throwing, and striking since these skills tend to be lowest for girls in comparison to boys scores (Cooley, Oakman, McNaughton, \& Ryska, 1997).

There is also limited research examining the influence of the severity of visual impairment upon motor skill performance. Much of such research has focused upon the level of visual impairment upon balance (Haibach, Lieberman, \& Pritchett, 2011; Häkkinen, Holopainen, Kautianen, Sillanpää, \& Häkkinen, 2006; Pereira, 1990; Johnson Kramer, Sherwood, French, \& Canabal, 1992; Ribadi, Rider, \& Toole, 1987; Wyver \& Livesey, 2003) finding mixed results. Leonard (1969) found no relationship between the level of visual impairment and performance on balance tasks, while Haibach et al. (2011), Pereira (1990), and Wyver and Livesey (2003) found better balance was related to increased residual vision. Several studies established a relationship between children and adolescents who are blind performing better than their sighted peers wearing blindfolds, revealing that the individuals who are blind adapt to their condition (Haibach et al., 2011; Johnson Kramer et al., 1992; Ribadi et al., 1987); however, Häkkinen et al. (2006) did not find better balance in children who were blind in comparison to their blindfolded sighted peers. Weak results were also found for manual dexterity and severity of visual impairment indicating better performances for some tasks in children with low vision (Houwen, Hartman, \& Visscher, 2008; Reimer et al., 1999; Wyver \& Livesey, 2003) and no differences were found in regard to gross motor skills (Houwen, Visscher, Hartman, \& Lemmink, 2007). Further research needs to be conducted in this area to establish a relationship between severity of visual impairment and gross motor skills in children.

\section{Study aim and hypotheses}

The aim of this study was to provide comprehensive research on gross motor skill performance in regard to age, gender, and level of visual impairment as defined by the United States Association of Blind Athletes (USABA). To examine these delays, we questioned whether there are differences in these three variables across the 12 fundamental motor skills assessed in the Test of Gross Motor Development Second edition (TGMD II)(Ulrich, 2000). Considering that minimal research findings have been published in regard to fundamental motor skills in children with visual impairments, some of our assumptions were based upon research findings in sighted children; we hypothesized significant differences between (1) older and younger children, (2) boys and girls, and (3) children with varying levels of visual impairment.

\section{Methods}

\subsection{Participants and recruitment}

A total of 100 children with visual impairments aged 612 years (mean age $=9.97$ years; SD $=1.62 ; 61$ boys: mean age $=9.92$ years; $S D=1.51 ; 39$ girls: mean age $=10.05$ years; $S D=1.79$ ) but no other disabilities were included in this cross sectional study. Children with visual impairments (CWVI) were recruited from seven camps for CWVI across the United States (AK, AZ, CA, CT, MD, and NY) during the course of one summer. Within the study group, the full range of visual impairments according to United States Association for Blind Athletes (USABA; B3 = best corrected vision between 20/200 and 20/599, legally blind; B2 = best corrected vision between 20/600 and up, travel vision; B1 = totally blind) was assessed. Parents reported their child's visual acuity level obtained from their child's optometrist. Table 1 shows the distribution of participants among the study groups. Institutional Review Board approval was obtained from the two universities of the researchers prior to this study. Each participant and their parent agreed to participate by signing informed consent forms. 
Table 1

Sample characteristics (absolute frequency).

\begin{tabular}{lcrrrr}
\hline & Age (years) & B3 & B2 & B1 \\
\hline Boys & $6-9$ & 9 & 7 & 4 & 20 \\
\multirow{2}{*}{ Girls } & $10-12$ & 22 & 9 & 10 & 3 \\
& $6-9$ & 7 & 1 & 6 \\
$N$ & $10-12$ & 14 & 8 & 25 & 23 \\
\hline
\end{tabular}

\subsection{Measures}

The Test of Gross Motor Development II (TGMD II; Ulrich, 2000) was used to determine participants' gross motor performance in all study groups. Scores from typically developing children in comparison to children who are blind can be found in Wagner et al. (2013). The TGMD II, which is validated for children with visual impairments (Houwen, Hartman, Jonker, \& Visscher, 2010), covers six locomotor skills (running, galloping, hopping, leaping, jumping, and sliding) as well as six object control skills (striking, dribbling, catching, kicking, throwing, and rolling). 'The internal consistency of the TGMD 2 was found to be high (alpha $=0.710 .72$ ) as well as the interrater, intrarater, and test retest reliability scores (ICCs ranging from 0.82 to 0.95 )' (Houwen et al., 2010, p. 143). In the current study, the TGMD II was modified in order to enable the children with visual impairments to perform all tasks (e.g. sound box for locomotor skills, fluorescent tape around bean bag for the leap, beep baseball for batting, wiffle ball with bells inside for the catch (see Lieberman et al., 2014)). These modifications are the same as validated in the Houwen et al. (2010) study and are listed in Wagner et al. (2013). Participants were allowed to manipulate the balls prior to performing the object control skills and were given the opportunity to receive additional instruction and/or feel the movement prior to performing a motor skill.

Locomotor and object control skills were further assessed using three to five process oriented components. Each criterion was evaluated as a one, if that criterion was present, or a zero if it was not. Each motor skill was performed two times. Scores were then totaled for each motor skill and for overall locomotor and overall object control skills for a total of 48 points. The order of the testing procedure followed the TGMD II manual for each child.

\subsection{Data analysis}

All motor skill assessments were recorded with a video device. The video recordings were used as the basis of the data analysis. Results were listed on the protocol sheet and transferred to SPSS 20.0. The impact of age, gender, and severity of impairment was analyzed simultaneously by use of generalized linear models (two tailed with $\alpha=.05$ ). Effects are calculated as $\sqrt{ } x^{2} / N$ or $d \quad(2 * T) / \sqrt{ } d f$ (in case of pairwise comparisons) and considered as small $(w>0.1 ; d>0.2)$, moderate $(w>0.3 ; d>0.5)$ or large $(w>0.2 ; d>0.8)$, respectively.

\section{Results}

The most significant effect between the children with visual impairments and their typically sighted peers was found in the children who are blind (B1's) (Wagner et al., 2013). The following results detail the differences among the three groups of children with visual impairments, B1's, B2's, and B3's, as well as age and gender differences (Table 2).

\subsection{Locomotor performance}

Analysis of locomotor performance (see Table 3) indicates no significant difference between 69 and 1012 year olds or boys and girls, respectively. Children at the B3 level performed significantly better than children at the B1 level (large effect); further, pairwise comparisons (see Table 4) showed that children at the B2 level performed significantly better than children at the B1 level (large effect).

A detailed analysis of the impact of severity of impairment on corresponding locomotor skills (see Tables 3 and 4) showed, that significant differences between all three groups could only be found in the run, whereas significant differences in galloping, hopping, leaping, and sliding could only be detected in comparison to children at the B1 level; thus, B3 and B2 showed comparable performances in these skills. Most of the significant differences represent large effects. No significant difference between any of the three impairment groups was found in jumping.

\subsection{Object control performance}

Analysis of object control performance (see Table 5) makes it clear, that 1012 year olds performed significantly better than 69 year olds and that boys outperformed girls (both small effects). Children who were at the B3 level performed significantly better than children who are at the B2 (small effect) or B1 (large effect) level; further, pairwise comparisons 
Table 2

Locomotor and object control skill performances by age, gender and severity of impairment $(N=100)$.

\begin{tabular}{|c|c|c|c|c|c|c|c|c|c|c|c|c|c|c|}
\hline & \multicolumn{2}{|c|}{$6-9(N=31)$} & \multicolumn{2}{|c|}{$10-12(N=69)$} & \multicolumn{2}{|c|}{ Boys $(N=61)$} & \multicolumn{2}{|c|}{ Girls $(N=39)$} & \multicolumn{2}{|c|}{ B3 $(N=52)$} & \multicolumn{2}{|c|}{ B2 $(N=25)$} & \multicolumn{2}{|c|}{ B1 $(N=23)$} \\
\hline & M & SD & M & SD & M & SD & M & SD & M & SD & M & SD & M & SD \\
\hline Locomotor & 28.45 & 7.68 & 29.91 & 7.63 & 29.44 & 7.75 & 29.49 & 7.55 & 32.87 & 5.92 & 30.28 & 5.35 & 20.87 & 6.68 \\
\hline Run & 5.32 & 2.55 & 5.46 & 2.44 & 5.62 & 2.42 & 5.10 & 2.52 & 6.67 & 1.40 & 5.48 & 1.87 & 2.52 & 2.52 \\
\hline Gallop & 4.55 & 1.96 & 4.81 & 2.02 & 4.72 & 2.03 & 4.74 & 1.97 & 5.13 & 1.74 & 4.88 & 2.01 & 3.65 & 2.21 \\
\hline Hop & 4.81 & 2.40 & 5.45 & 1.55 & 5.36 & 1.93 & 5.08 & 1.77 & 5.75 & 1.44 & 5.40 & 1.63 & 3.96 & 2.36 \\
\hline Leap & 2.90 & 1.66 & 2.96 & 1.65 & 2.70 & 1.59 & 3.31 & 1.69 & 3.56 & 1.34 & 3.20 & 1.29 & 1.26 & 1.51 \\
\hline Jump & 3.90 & 2.09 & 4.13 & 1.88 & 3.92 & 1.84 & 4.28 & 2.09 & 4.31 & 2.02 & 4.08 & 2.14 & 3.48 & 1.41 \\
\hline Slide & 6.94 & 1.91 & 6.91 & 1.79 & 6.93 & 1.83 & 6.90 & 1.82 & 7.21 & 1.64 & 7.16 & 0.90 & 6.00 & 2.58 \\
\hline Object & 29.94 & 8.45 & 32.54 & 9.35 & 33.15 & 8.27 & 29.51 & 10.03 & 35.90 & 7.13 & 32.44 & 8.08 & 21.52 & 5.88 \\
\hline Strike & 7.58 & 2.11 & 7.74 & 1.87 & 8.03 & 1.82 & 7.15 & 2.02 & 8.21 & 1.81 & 8.08 & 1.94 & 6.09 & 1.31 \\
\hline Dribble & 4.13 & 3.02 & 5.58 & 2.46 & 5.54 & 2.59 & 4.49 & 2.81 & 5.96 & 2.34 & 5.44 & 2.62 & 2.91 & 2.47 \\
\hline Catch & 2.77 & 1.09 & 3.07 & 1.58 & 2.97 & 1.32 & 3.00 & 1.65 & 3.58 & 1.59 & 2.44 & 1.04 & 2.22 & 0.80 \\
\hline Kick & 6.03 & 1.62 & 5.81 & 2.06 & 5.95 & 1.90 & 5.77 & 1.99 & 6.67 & 1.47 & 6.32 & 1.49 & 3.61 & 1.50 \\
\hline Throw & 4.71 & 2.19 & 4.94 & 2.52 & 5.49 & 2.16 & 3.90 & 2.50 & 5.81 & 2.03 & 4.68 & 2.53 & 2.96 & 1.94 \\
\hline Roll & 5.26 & 1.75 & 5.59 & 2.01 & 5.62 & 1.93 & 5.28 & 1.93 & 6.21 & 1.42 & 5.68 & 1.95 & 3.65 & 1.77 \\
\hline
\end{tabular}

Notes: $N$ : number of participants; M: mean; SD: standard deviation.

Table 3

Impact of age, gender and severity of impairment on locomotor skill performance $(N=100)$.

\begin{tabular}{|c|c|c|c|c|c|c|c|c|}
\hline & \multirow[t]{2}{*}{$\beta$-Weight } & \multirow[t]{2}{*}{ SE } & \multirow[t]{2}{*}{$X^{2}$} & \multirow[t]{2}{*}{$d f$} & \multirow[t]{2}{*}{$p$} & \multicolumn{2}{|l|}{$95 \% \mathrm{CI}$} & \multirow[t]{2}{*}{$w$} \\
\hline & & & & & & Low & High & \\
\hline \multicolumn{9}{|l|}{ Locomotor } \\
\hline $10-12^{\mathrm{a}}$ & 1.51 & 1.26 & 1.43 & 1 & 0.232 & -0.97 & 3.99 & 0.12 \\
\hline Boys $^{\mathrm{b}}$ & 0.09 & 1.20 & 0.01 & 1 & 0.940 & -2.26 & 2.44 & 0.01 \\
\hline $\mathrm{B} 1^{\mathrm{C}}$ & -12.00 & 1.46 & 67.41 & 1 & 0.000 & -14.87 & -9.14 & 0.82 \\
\hline$B 2^{\mathrm{c}}$ & -2.57 & 1.42 & 3.27 & 1 & 0.072 & -5.36 & 0.22 & 0.18 \\
\hline Intercept & 31.77 & 1.41 & 506.76 & 1 & 0.000 & 29.00 & 34.53 & \\
\hline \multicolumn{9}{|l|}{ Run } \\
\hline $\mathrm{B} 1^{\mathrm{C}}$ & -4.15 & 0.45 & 84.97 & 1 & 0.000 & -5.03 & -3.27 & 0.92 \\
\hline $\mathrm{B}^{\mathrm{C}}$ & -1.19 & 0.44 & 7.43 & 1 & 0.006 & -2.05 & -0.34 & 0.27 \\
\hline Intercept & 6.67 & 0.25 & 715.96 & 1 & 0.000 & 6.18 & 7.16 & \\
\hline \multicolumn{9}{|l|}{ Gallop } \\
\hline$B 1^{\mathrm{c}}$ & -1.48 & 0.47 & 9.79 & 1 & 0.002 & -2.41 & -0.55 & 0.31 \\
\hline $\mathrm{B}^{\mathrm{C}}$ & -0.26 & 0.46 & 0.31 & 1 & 0.580 & -1.16 & 0.65 & 0.06 \\
\hline Intercept & 5.14 & 0.26 & 383.04 & 1 & 0.000 & 4.62 & 5.65 & \\
\hline \multicolumn{9}{|l|}{ Hop } \\
\hline $\mathrm{B} 1^{\mathrm{C}}$ & -1.79 & 0.43 & 17.52 & 1 & 0.000 & -2.63 & -0.95 & 0.42 \\
\hline $\mathrm{B}^{\mathrm{c}}$ & -0.35 & 0.42 & 0.71 & 1 & 0.401 & -1.17 & 0.47 & 0.08 \\
\hline Intercept & 5.75 & 0.24 & 587.36 & 1 & 0.000 & 5.29 & 6.22 & \\
\hline \multicolumn{9}{|l|}{ Leap } \\
\hline $\mathrm{B} 1^{\mathrm{C}}$ & -2.30 & 0.34 & 46.41 & 1 & 0.000 & -2.96 & -1.64 & 0.68 \\
\hline $\mathrm{B}^{\mathrm{c}}$ & -0.36 & 0.33 & 1.19 & 1 & 0.275 & -1.00 & 0.29 & 0.11 \\
\hline Intercept & 3.56 & 0.19 & 363.11 & 1 & 0.000 & 3.19 & 3.92 & \\
\hline \multicolumn{9}{|l|}{ Jump } \\
\hline $\mathrm{B} 1^{\mathrm{C}}$ & -0.83 & 0.48 & 3.04 & 1 & 0.081 & -1.76 & 0.10 & 0.17 \\
\hline$B 2^{\mathrm{c}}$ & -0.23 & 0.46 & 0.24 & 1 & 0.622 & -1.13 & 0.68 & 0.05 \\
\hline Intercept & 4.31 & 0.26 & 267.55 & 1 & 0.000 & 3.79 & 4.82 & \\
\hline \multicolumn{9}{|l|}{ Slide } \\
\hline $\mathrm{B} 1^{\mathrm{C}}$ & -1.21 & 0.44 & 7.75 & 1 & 0.005 & -2.07 & -0.36 & 0.28 \\
\hline$B 2^{\mathrm{c}}$ & -0.05 & 0.42 & 0.02 & 1 & 0.903 & -0.88 & 0.78 & 0.01 \\
\hline Intercept & 7.21 & 0.24 & 895.37 & 1 & 0.000 & 6.74 & 7.68 & \\
\hline
\end{tabular}

Notes: Locomotor: $-2 L L=52.73 ; d f=4 ; p=0.000 ;$ run: $-2 L L=61.52 ; d f=2 ; p=0.000 ;$ gallop: $-2 L L=9.53 ; d f=2 ; p=0.009 ;$ hop: $-2 L L=16.37 ; d f=2$; $p=0.000$; leap: $-2 L L=38.97 ; d f=2 ; p=0.000$; jump: $-2 L L=3.00 ; d f=2 ; p=0.223$; slide: $-2 L L=8.05 ; d f=2 ; p=0.018$. SE: standard error, $d f$ : degrees of freedom; CI: confidence interval.

$p<0.05$ values have been bolded.

a $6-9$ year olds as reference.

b Girls as reference.

c B3 as reference. 
Table 4

Differences in locomotor skill performance between B1 and B2 $(N=48)$.

\begin{tabular}{|c|c|c|c|c|c|c|c|}
\hline & \multirow[t]{2}{*}{$I-J$} & \multirow[t]{2}{*}{ SE } & \multirow[t]{2}{*}{$d f$} & \multirow[t]{2}{*}{ Adj. $p^{\mathrm{a}}$} & \multicolumn{2}{|l|}{$95 \% \mathrm{CI}$} & \multirow[t]{2}{*}{$d$} \\
\hline & & & & & Low & High & \\
\hline Locomotor & -9.43 & 1.69 & 1 & 0.000 & -13.21 & -5.65 & -1.65 \\
\hline Run & -2.96 & 0.52 & 1 & 0.000 & -4.12 & -1.79 & -1.68 \\
\hline Gallop & -1.23 & 0.55 & 1 & 0.049 & -2.45 & 0.00 & -0.66 \\
\hline Hop & -1.44 & 0.49 & 1 & 0.008 & -2.55 & -0.34 & -0.87 \\
\hline Leap & -1.94 & 0.39 & 1 & 0.000 & -2.81 & -1.07 & -1.47 \\
\hline Jump & -0.60 & 0.55 & 1 & 0.546 & -1.83 & 0.63 & -0.32 \\
\hline Slide & -1.16 & 0.50 & 1 & 0.042 & -2.29 & -0.03 & -0.68 \\
\hline
\end{tabular}

Notes: I-J: mean difference; SE: standard error, $d f$ : degrees of freedom; CI: confidence interval.

$p<0.05$ values have been bolded.

a Bonferroni-Holm method.

Table 5

Impact of age, gender and severity of impairment on object control skill performance $(N=100)$.

\begin{tabular}{|c|c|c|c|c|c|c|c|c|}
\hline & \multirow[t]{2}{*}{$\beta$-Weight } & \multirow[t]{2}{*}{ SE } & \multirow[t]{2}{*}{$X^{2}$} & \multirow[t]{2}{*}{$d f$} & \multirow[t]{2}{*}{$p$} & \multicolumn{2}{|l|}{$95 \% \mathrm{CI}$} & \multirow[t]{2}{*}{$w$} \\
\hline & & & & & & Low & High & \\
\hline \multicolumn{9}{|l|}{ Object } \\
\hline $10-12^{\mathrm{a}}$ & 2.84 & 1.44 & 3.91 & 1 & 0.048 & 0.02 & 5.66 & 0.20 \\
\hline Boys $^{b}$ & 3.86 & 1.37 & 8.00 & 1 & 0.005 & 1.19 & 6.54 & 0.28 \\
\hline $\mathrm{B} 1^{\mathrm{C}}$ & -14.44 & 1.66 & 75.27 & 1 & 0.000 & -17.70 & -11.18 & 0.87 \\
\hline $\mathrm{B} 2^{\mathrm{C}}$ & -3.60 & 1.62 & 4.94 & 1 & 0.026 & -6.77 & -0.43 & 0.22 \\
\hline Intercept & 31.63 & 1.61 & 387.62 & 1 & 0.000 & 28.49 & 34.78 & \\
\hline \multicolumn{9}{|l|}{ Strike } \\
\hline $10-12^{\mathrm{a}}$ & 0.22 & 0.36 & 0.36 & 1 & 0.549 & -0.49 & 0.92 & 0.06 \\
\hline Boys $^{\mathrm{b}}$ & 0.89 & 0.34 & 6.85 & 1 & 0.009 & 0.22 & 1.56 & 0.26 \\
\hline $\mathrm{B} 1^{\mathrm{C}}$ & -2.14 & 0.42 & 26.48 & 1 & 0.000 & -2.95 & -1.32 & 0.51 \\
\hline$B 2^{\mathrm{c}}$ & -0.17 & 0.40 & 0.17 & 1 & 0.677 & -0.96 & 0.62 & 0.04 \\
\hline Intercept & 7.53 & 0.40 & 353.04 & 1 & 0.000 & 6.75 & 8.32 & \\
\hline \multicolumn{9}{|l|}{ Dribble } \\
\hline $10-12^{\mathrm{a}}$ & 1.52 & 0.48 & 9.84 & 1 & 0.002 & 0.57 & 2.47 & 0.31 \\
\hline Boys $^{\mathrm{b}}$ & 1.14 & 0.46 & 6.11 & 1 & 0.013 & 0.24 & 2.04 & 0.25 \\
\hline $\mathrm{B} 1^{\mathrm{C}}$ & -3.07 & 0.56 & 29.93 & 1 & 0.000 & -4.17 & -1.97 & 0.55 \\
\hline $\mathrm{B} 2^{\mathrm{c}}$ & -0.55 & 0.55 & 1.03 & 1 & 0.311 & -1.62 & 0.52 & 0.10 \\
\hline Intercept & 4.23 & 0.54 & 61.07 & 1 & 0.000 & 3.17 & 5.29 & \\
\hline \multicolumn{9}{|l|}{ Catch } \\
\hline $10-12^{a}$ & 0.29 & 0.28 & 1.11 & 1 & 0.293 & -0.25 & 0.84 & 0.11 \\
\hline Boys $^{\mathrm{b}}$ & 0.02 & 0.27 & 0.00 & 1 & 0.956 & -0.51 & 0.54 & 0.00 \\
\hline $\mathrm{B} 1^{\mathrm{C}}$ & -1.36 & 0.32 & 17.69 & 1 & 0.000 & -2.00 & -0.73 & 0.42 \\
\hline $\mathrm{B}^{\mathrm{c}}$ & -1.13 & 0.31 & 12.99 & 1 & 0.000 & -1.75 & -0.52 & 0.36 \\
\hline Intercept & 3.37 & 0.31 & 116.04 & 1 & 0.000 & 2.75 & 3.98 & \\
\hline \multicolumn{9}{|l|}{ Kick } \\
\hline $10-12^{\mathrm{a}}$ & -0.20 & 0.31 & 0.39 & 1 & 0.530 & -0.81 & 0.42 & 0.06 \\
\hline Boys $^{b}$ & 0.18 & 0.30 & 0.37 & 1 & 0.546 & -0.40 & 0.76 & 0.02 \\
\hline $\mathrm{B} 1^{\mathrm{C}}$ & -3.07 & 0.36 & 71.14 & 1 & 0.000 & -3.78 & -2.35 & 0.84 \\
\hline $\mathrm{B}^{\mathrm{c}}$ & -0.36 & 0.35 & 1.06 & 1 & 0.304 & -1.06 & 0.33 & 0.10 \\
\hline Intercept & 6.70 & 0.35 & 364.79 & 1 & 0.000 & 6.01 & 7.39 & \\
\hline \multicolumn{9}{|l|}{ Throw } \\
\hline $10-12^{\mathrm{a}}$ & 0.32 & 0.42 & 0.57 & 1 & 0.450 & -0.51 & 1.15 & 0.08 \\
\hline Boys $^{\text {b }}$ & 1.64 & 0.40 & 16.78 & 1 & 0.000 & 0.86 & 2.43 & 0.41 \\
\hline $\mathrm{B} 1^{\mathrm{c}}$ & -2.87 & 0.49 & 34.51 & 1 & 0.000 & -3.83 & -1.91 & 0.59 \\
\hline $\mathrm{B} 2^{\mathrm{c}}$ & -1.20 & 0.48 & 6.32 & 1 & 0.012 & -2.13 & -0.26 & 0.25 \\
\hline Intercept & 4.61 & 0.47 & 95.24 & 1 & 0.000 & 3.68 & 5.53 & \\
\hline \multicolumn{9}{|l|}{ Roll } \\
\hline $10-12^{\mathrm{a}}$ & 0.36 & 0.35 & 1.10 & 1 & 0.294 & -0.32 & 1.05 & 0.10 \\
\hline Boys $^{\text {b }}$ & 0.37 & 0.33 & 1.27 & 1 & 0.260 & -0.28 & 1.02 & 0.11 \\
\hline $\mathrm{B} 1^{\mathrm{c}}$ & -2.57 & 0.40 & 40.75 & 1 & 0.000 & -3.35 & -1.78 & 0.64 \\
\hline $\mathrm{B} 2^{\mathrm{C}}$ & -0.54 & 0.39 & 1.93 & 1 & 0.164 & -1.31 & 0.22 & 0.14 \\
\hline Intercept & 5.74 & 0.39 & 218.75 & 1 & 0.000 & 4.98 & 6.50 & \\
\hline
\end{tabular}

Notes: Object control: $-2 L L=62.30 ; d f=4 ; p=0.000 ;$ strike: $-2 L L=30.09 ; d f=4 ; p=0.000 ;$ dribble: $-2 L L=37.46 ; d f=4 ; p=0.000 ;$ catch: $-2 L L=21.98$; $d f=4 ; p=0.000$; kick: $-2 L L=55.93 ; d f=4 ; p=0.000$; throw: $-2 L L=41.48 ; d f=4 ; p=0.000 ;$ roll: $-2 L L=35.97 ; d f=4 ; p=0.000 ; S E$ : standard error, $d f$ : degrees of freedom; $\mathrm{CI}$ : confidence interval.

$p<0.05$ values have been bolded.

a 6-9 year olds as reference.

b Girls as reference.

c B3 as reference. 
Table 6

Differences in object control skill performance between B1 and B2 $(N=48)$.

\begin{tabular}{|c|c|c|c|c|c|c|c|}
\hline & \multirow[t]{2}{*}{$I-J$} & \multirow[t]{2}{*}{ SE } & \multirow[t]{2}{*}{$d f$} & \multirow[t]{2}{*}{ Adj. $p^{\mathrm{a}}$} & \multicolumn{2}{|l|}{$95 \% \mathrm{CI}$} & \multirow[t]{2}{*}{$d$} \\
\hline & & & & & Low & High & \\
\hline Object & -10.84 & 1.92 & 1 & 0.000 & -15.15 & -6.54 & -1.66 \\
\hline Strike & -1.97 & 0.48 & 1 & 0.000 & -3.04 & -0.89 & -1.21 \\
\hline Dribble & -2.52 & 0.65 & 1 & 0.000 & -3.97 & -1.06 & -1.14 \\
\hline Catch & -0.23 & 0.37 & 1 & 0.544 & -0.96 & 0.51 & -0.18 \\
\hline Kick & -2.70 & 0.42 & 1 & 0.000 & -3.64 & -1.76 & -1.90 \\
\hline Throw & -1.68 & 0.56 & 1 & 0.006 & -2.94 & -0.41 & -0.88 \\
\hline Roll & -2.02 & 0.46 & 1 & 0.000 & -3.06 & -0.98 & -1.29 \\
\hline
\end{tabular}

Notes: $I-J=$ mean difference; SE: standard error, $d f$ : degrees of freedom; CI: confidence interval.

$p<0.05$ values have been bolded.

a Bonferroni-Holm method.

(see Table 6) showed that children who are at the B2 level performed significantly better than children who are at the B1 level (large effect).

A detailed analysis of corresponding object control skills (see Table 5) revealed, that the 1012 year olds only performed significantly better than 69 year olds in dribbling (moderate effect) and that boys only outperformed girls in striking, dribbling (both small effects), and throwing (moderate effect). With regard to the impact of severity of impairment (see Tables 5 and 6), results indicated that significant differences between all three groups could only be found in the throw (small to large effects), whereas striking, dribbling, kicking, and rolling differences could only be detected in comparison to children who are at the B1 level (large effects); thus, B3 and B2 showed comparable performances in these skills. Finally, children who were at the B3 level outperformed children who were at the B2 or B1 level in catching (both moderate effects) with no significant differences between B2 and B1.

\section{Discussion}

\subsection{Summary and progress of knowledge}

The present study provided novel data because it explicitly focused upon the influence of age, gender, and severity of visual impairment on gross motor skills in children with visual impairments for six locomotor and six object control skills. Prior research has established that performance of motor skills by children with visual impairments is significantly lower than sighted children (Brambring, 2006; Houwen et al., 2007; Wagner et al., 2013), as such, controls were not included in this analysis. The focus was upon the impact of these three variables within the group of children with visual impairments. To further the previous research, the current investigation assessed twelve motor skills. It was found that the severity of the visual impairment was a significant factor in the performance of all of the assessed motor skills, particularly for the children at the B1 level in comparison to the children at the B2 or B3 levels. These children performed at a significantly lower level than either of the other groups in nearly every motor skill. The children at the B2 and B3 levels performed with similar performances in all but three of the motor skills assessed, the run, catch, and throw.

Previous to this research, there was insufficient evidence to establish the effects of age or gender on individual gross motor skills in children with visual impairments. The results of the present research concluded that age and gender did not play an important role in most of the assessed gross motor skills. There were no significant gender differences for any of the locomotor skills, but similar to research in typically developing children (Barnett et al., 2010; Butterfield \& Loovis, 1998; Butterfield et al., 2012; Thomas \& French, 1985), boys outperformed girls in several of the object control skills (i.e., strike, dribble, and throw). It is likely that interventions with a focus upon improving mechanics will yield similar enhanced improvements in girls over boys as has been found in sighted children (Thomas et al., 1994).

The result that age was not an important factor in children with visual impairments counters typical gross motor development, as it is generally an important variable in gross motor skill performance throughout childhood (Butterfield et al., 2012; Ulrich, 2000; Vandorpe et al., 2011). Children who are older typically have better motor skills than younger children with visual impairments. In the present study, significant effects for age were only found in one of the twelve fundamental motor skills assessed, dribbling. It should be noted that this was a cross sectional study, so it can only be assumed that these changes were age related. However, these results reveal that there may be a lack of improvement found in most gross motor skills indicating a particularly strong need for increased opportunities to develop motor skills in children with visual impairments. This age range is a critical time period for the development of fundamental motor skills. Reduced physical activity with age may be a contributing factor in the trend toward a lack of age differences in motor development found in the current study as previous research has found that children with visual impairments, were progressively less active with age (Kozub \& Oh, 2004a, 2004b).

\subsection{Practical implications}

There is a great need for intentional and specific instruction on motor skills at a younger age to be most effective for children with visual impairments. Specifically, this study exposed the critical need to improve fundamental motor skills in 
children with visual impairments, particularly children who are totally blind. Instruction on motor skills must be conducted with plenty of time and tactile methods. This instruction must be conducted by someone who knows the skills and how to teach them in a methodical and tactical manner either at home or school. If these skills are taught at school, they can be conducted during pre teaching, which is time set aside for children to learn skills that will be included in their physical education curriculum at a later time (Lieberman, Ponchillia, \& Ponchillia, 2013). Small group self contained physical education classes are another method for introducing and further developing fundamental motor skills in children with visual impairments.

Knowing that the results revealed large disparities in performance between children who are blind (B1) in comparison to their partially sighted peers (B2, B3) gives direction for instruction and future research. It is known that children who are blind need more tactile teaching methods, such as tactile modeling and physical guidance (Lieberman et al., 2013; O'Connell, Lieberman, \& Petersen, 2006). It has also been found that children with visual impairments need many repetitions with feedback in order to learn novel skills (Farrenkopf \& McGregor, 2006). If these skills are taught at home, the family should be given a check list with clear instructions on each skill and communication with the family should be ongoing to ensure appropriate opportunities for the student (Perkins et al., 2013).

\subsection{Limitations and future perspectives}

Data collection occurred at summer camps, many of which were sports camps. Children who attend sports camps may be more athletic and/or perceive themselves as more athletic, which may increase their performance on the assessments (Shapiro et al., 2005). The performances of children with a higher perceived competence would likely be better than that of the general population of children with visual impairments. A replication of the findings in such a population would enable more robust generalizations. Future research should examine the effectiveness of developmentally appropriate practice on young children with visual impairments in an effort to decrease and potentially eliminate the age gap between sighted children and children with visual impairments.

\section{Conclusion}

In an assessment of age, gender, and severity of visual impairment, it was found that level of visual impairment impacted children with a B1 level most severely; older children only performed better for dribbling than the younger children; and boys only performed better at some object control skills in comparison to girls. There is an overall need to include more instruction and opportunities for children with visual impairments on these skills throughout school and home life to better promote motor skill development.

\section{Conflict of interest}

The authors declare that there is no actual or potential conflict of interest.

\section{Acknowledgements}

The authors would like to thank the American Printing House for the Blind and the Fetzer Institute (Grant Number 3123.00) for their financial support for this research project.

\section{References}

Barnett, L. M., van Beurden, E., Morgan, P. J., Brooks, L. O., \& Beard, J. R. (2010). Gender differences in motor skill proficiency from childhood to adolescence: A longitudinal study. Research Quarterly for Exercise and Sport, 81(2), 162-170.

Bouchard, D., \& Tetreault, S. (2000). The motor development of sighted children and children with moderate low vision aged 8-13. Journal of Visual Impairment E Blindness, 94, 564-573.

Brambring, M. (2006). Divergent development of gross motor skills in children who are blind or sighted. Journal of Visual Impairment E' Blindness, 620-634.

Butterfield, S. A., \& Loovis, E. M. (1998). Influence of age, gender, balance, and sports participation on development of throwing by children in Grades K-8. Perceptual and Motor Skills, 76, 459-464.

Butterfield, S. A., Angell, R. M., \& Mason, C. A. (2012). Age and gender differences in object control skills by children ages 5 to 14. Perceptual and Motor Skills, 114(1), $261-274$

Conroy, P. (2012). Supporting students with visual impairments in physical education. Insight: Research and Practice in Visual Impairment and Blindness, 5(1), 3-10. Cooley, D., Oakman, R., McNaughton, L., \& Ryska, T. (1997). Fundamental movement patterns of Tasmanian primary school children. Perceptual and Motor Skills, 84, 307-316.

Farrenkopf, C., \& McGregor, D. (2006). Physical education and health. In A. J. Koenig \& M. C. Holbrook (Eds.), Foundations of education (2nd ed.). New York, NY: American Foundation for the Blind.

Gipsman, S. C. (1981). Effect of visual condition on use of proprioceptive cues in performing a balance task. Journal of visual impairment and blindness, 75, 50-54.

Haibach, P., Lieberman, L., \& Pritchett, J. (2011). Balance in adolescents with and without visual impairments. Journal of Visual Impairment and Blindness, 4, 112123

Häkkinen, A., Holopainen, E., Kautianen, H., Sillanpää, E., \& Häkkinen, K. (2006). Neuromuscular function and balance of prepubertal and pubertal blind and sighted boys. Acta Paediatrica, 95, 1277-1283.

Holbrook, E. A., Caputo, J., Fuller, D., Perry, T., \& Morgan, D. (2009). Physical activity, body composition, and perceived quality of life in adults with visual impairment. Journal of Visual Impairment and Blindness, 103(1), 17-29. 
Houwen, S., Visscher, C., Hartman, E., \& Lemmink, K. A. P. M. (2007). Gross motor skills in sports participation of children with visual impairments. Research Quarterly for Exercise and Sport, 78, 16-23.

Houwen, S., Hartman, E., \& Visscher, C. (2008). Physical activity and motor skills in children with and without visual impairments. Medicine E Science in Sports E Exercise, 103-109. http://dx.doi.org/10.1249/MSS.0b013e318183389d

Houwen, S., Visscher, C., Lemmink, K. A. P., \& Hartman, M. E. (2009). Motor skill performance of children and adolescents with visual impairments: A review. Exceptional Children, 75, 464-492.

Houwen, S., Hartman, E., Jonker, L., \& Visscher, C. (2010). Reliability and validity of the TGMD-2 in primary-school-age children with visual impairments. Adapted Physical Activity Quarterly, 27, 143-159.

Johnson-Kramer, C., Sherwood, D., French, R., \& Canabal, M. Y. (1992). Performance and learning of a dynamic balance task by visually impaired children. Clinical Kinesiology, (Winter), 3-6.

Joseph, D. P. (1984). The effects of augmented verbal information feedback in the motor skill learning of totally blind subjects seven to twenty-one years of age. Unpublished doctoral dissertation. Columbus: The Ohio State University.

Kozub, F. M., \& Oh, H. (2004a). An exploratory study of physical activity levels in children and adolescents with visual impairments. Clinical Kinesiology, 55(3), 1-7. Kozub, F. M., \& Oh, H. K. (2004b). An exploratory study of physical activity levels in children and adolescents with visual impairments. Clinical Kinesiology, 58, $1-7$. Leonard, J. A. (1969). Static and mobile balancing performance of blind adolescent grammar school children. The New Outlook, 63, 65-72.

Lieberman, L. J., \& MacVicar, J. (2003). Play and recreation habits of youth who are deaf-blind. Journal of Visual Impairment and Blindness, 97(12), 755-768.

Lieberman, L. J., Houston-Wilson, C., \& Kozub, F. (2002). Perceived barriers to including students with visual impairments and blindness into physical education. Adapted Physical Activity Quarterly, 19(3), 364-377.

Lieberman, L. J., Ponchillia, P., \& Ponchillia, S. (2013). Physical education and sport for individuals who are visually impaired or deafblind: Foundations of instruction. New York, NY: American Federation of the Blind Press.

Lieberman, L. J., Haibach, P. S., \& Wagner, M. O. (2014). Let’s play together: Sports equipment for children with and without visual impairments. Palaestra, 28(2), $13-15$.

O'Connell, M., Lieberman, L., \& Petersen, J. S. (2006). The use of tactile modeling and physical guidance as instructional strategies in physical activity for children who are blind. Journal of Visual Impairment E' Blindness, 100, 471-477.

Pereira, L. M. (1990). Spatial concepts and balance performance: Motor learning in blind and visually impaired children. Journal of Visual Impairment \& Blindness, $84,109-111$.

Perkins, K., Columna, L., Lieberman, L. J., \& Bailey, J. (2013). Parental perceptions toward physical activity for their children with visual impairments and blindness. Journal of Visual Impairments and Blindness, 107, 131-142.

Reimer, A. M., Smits-Engelsman, B. C. M., \& Siemonsma-Boom, M. (1999). Development of an instrument to measure manual dexterity in children with visual impairments aged 6-12. Journal of Visual Impairment \& Blindness, 93, 643-658.

Ribadi, H., Rider, R. A., \& Toole, T. (1987). Comparison of static and dynamic balance in congenitally blind, sighted, and sighted blindfolded adolescents. Adapted Physical Activity Quarterly, 4, 220-225.

Shapiro, D., Moffett, A., Lieberman, L. J., \& Dummer, G. (2005). Perceived competence of children with visual impairments. Journal of Visual Impairment and Blindness, 99, 15-25.

Thomas, J. R., \& French, K. E. (1985). Gender differences across age in motor performance. Psychological Bulletin, 98, $260-282$.

Thomas, J. R., Michael, D., \& Gallagher, J. D. (1994). Effects of training on gender differences in overhand throwing: A brief quantitative literature analysis. Research Quarterly for Exercise and Sport, 65, 67-71.

Ulrich, D. (2000). Test of gross motor development (2nd ed.). Austin, TX: Pro-Ed.

Vandorpe, B., Vandendriessche, J., Lefevre, J., Pion, J., Vaeyens, R., Matthys, S., et al. (2011). The Körperkoordinationstest für Kinder: Reference values and suitability for 6-12-year old children in Flanders. Scandinavian Journal of Medicine E Science in Sports, 21(3), 378-388.

Wagner, W. O., Haibach, P. S., \& Lieberman, L. J. (2013). Gross motor skill performance in children with and without visual impairments - Research to practice. Research in Developmental Disabilities, 34, 3246-3252.

Wyver, S. R., \& Livesey, D. J. (2003). Kinaesthetic sensitivity and motor skills of school-aged children with a congenital visual impairment. British Journal of Visual Impairment, 21, 25-31. 